\title{
CROP INVENTORY OF ORCHARD CROPS IN INDIA USING REMOTELY SENSED DATA
}

\author{
Karshan Chaudhari ${ }^{1 *}$, Nilay Nishant ${ }^{2}$, Gargi Upadhyay ${ }^{1}$, Revati More ${ }^{1}$, Niti $\operatorname{Singh}^{1}$, Sarveshwar Prasad Vyas ${ }^{1}$ and \\ Bimal Kumar Bhattacharya ${ }^{1}$
}

${ }^{1}$ Space Applications Centre, ISRO, Ahmedabad, Gujarat - 380015

${ }^{2}$ North Eastern Space Applications Centre, ISRO, Umium, Meghalaya - 793103

Commission III, WG III/10

KEY WORDS: Orchard Crops, Mango, Banana, Citrus, ISO-DATA Clustering, Object oriented Classification

\begin{abstract}
:
The use of satellite remote sensing (RS) technologies for purpose of crop discrimination, mapping, area estimation, condition and yield assessment has been proved to be effective and efficient in terms of time and cost, having better consistency implemented with scientific approaches. However, application of satellite RS technology for horticultural crops in India has certain challenges due to scattered and small field sizes, comparatively short duration such as vegetable crops and mixed cropping. Hence the study was taken for developing research methodology for area assessment of three major fruit crops such as Banana, Mango and Citrus over 20 districts in four states viz. Gujarat, Madhya Pradesh, Uttar Pradesh and Bihar. Appropriate bio-window for analysing different crop types was selected and mapping of crops were done using pixel based hybrid classification i.e. un-supervised ISODATA clustering plus supervised MXL classification as well as object based classification of high resolution remote sensing data (Resourcesat LISS III and/or LISS IV, Cartosat - 1 PAN) followed by their accuracy assessment and their comparison with departmental reported statistics. Overall, the classification accuracy was more than $80 \%$ for all the crops. Deviation from statistics were in the range of 3 to $38 \%$. Higher deviations from statistics were mostly due to use of lower resolution satellite data or mixing of crops having similar spectral signatures e.g. mango and sapota in Navsari and Valsad districts of Gujarat. It was very difficult to discriminate the young orchards of 2-3 years from other field crops due to mixed / inter cropping practices. The maps were checked and certified by respective State Horticulture Departments and were archived in VEADS, SAC and BHUVAN, NRSC geoportals of ISRO. RISAT 1 (microwave) data were explored for the estimation of banana orchards in order to detect banana plantation at early stage and under cloudy sky conditions. There is huge potential of application in this sector using advanced observations from hyperspectral, thermal infrared sensors and advanced radars or LIDAR's on-board upcoming satellites.
\end{abstract}

\section{INTRODUCTION}

India is the second largest producer of fruits and vegetables in the world and occupies first position in the production of fruits like mango, banana, papaya, sapota, pomegranate, acid lime and aonla and vegetables like peas and okra (Anonymous, 2017). Horticulture plays a significant role in improving the productivity of land, generating employment, enhancing exports, improving economic conditions of the farmers and entrepreneurs, also providing food and nutritional security to the people (Usha and Singh, 2013). Horticulture crops are a major part of the revenue generation in India from the agricultural sector (Kimothi et al., 1997). Total Horticultural production, in recent years, has been estimated as higher than the food grain production in the country and India takes the 2nd position in the world in total horticultural production (Anonymous, 2017). However, the inventory (area and production estimates) of horticultural crops is not as standardized as the field crops, which may be due to scattered and small fields, variable seasons, multiple pickings, etc. (Ray et al., 2016).

The use of satellite remote sensing (RS) technologies for purpose of crop discrimination, mapping, area estimation, condition and yield assessment has been proved to be effective and efficient in terms of time and cost, having better consistency implemented with scientific approaches. The FASAL (Forecasting Agricultural output using Space, Agrometeorology and Land based observations) project of the Ministry of Agriculture, for which methodologies were developed by Space Applications Centre, ISRO, is being operationalised at Mahalanobis National Crop Forecast Centre to provide pre-harvest crop production forecasts of 8 major field crops using satellite data (Parihar and Oza, 2006; Ray and Neetu, 2017). However, there was no operational approach for using remote sensing for horticultural crop estimation. Many pilot studies have been carried out, which have been compiled in report by Panigrahy and Manjunath, 2009.

Application of satellite RS technology for horticultural crops in India has certain challenges due to scattered and small field sizes, comparatively short duration such as vegetable crops and mixed cropping. Hence, Department of Agriculture, Cooperation \& Farmers' Welfare of Ministry of Agriculture \& Farmers' Welfare under the Mission for Integrated Development of Horticulture (MIDH) initiated a project, in September 2014, called CHAMAN (Coordinated Horticulture Assessment and Management using geoiNformatics) for better horticulture inventory and management using remote sensing, GIS and collateral field data. Space Applications Centre (SAC), ISRO, Ahmedabad as the part of the project has taken the study for developing research methodology for area assessment of three major fruit crops such as Banana, Mango and Citrus over 20 districts in 4 states viz. Gujarat, Madhya Pradesh (MP), Uttar Pradesh (UP) and Bihar (Table 1, Figure 1). Major crops and their study areas were selected in consultation with state horticulture departments such that they comprised of about $70 \%$ share of the country's production and at least $55 \%$ of the area of a particular crop. Similar studies for other horticultural crops Viz. Aonla in Pratapgarh district, Mentha in Barabanki district and Guava in Kanpur district in Uttar Pradesh were also done 
by UP Remote Sensing Applications Centre, Lucknow in collaboration with SAC, Ahmedabad.

\begin{tabular}{|c|c|}
\hline Crop/ Studies & District \\
\hline & Single Crop Inventory \\
\hline Banana & Gujarat: Anand, Bharuch and Vadodara \\
\hline Mango & $\begin{array}{l}\text { Gujarat: Navasari, Valsad, Junagadh, Surat, } \\
\text { Bhavnagar } \\
\text { Uttar Pradesh: Lucknow, Faizabad, Varanasi } \\
\text { Bihar: Bhagalpur }\end{array}$ \\
\hline Citrus & $\begin{array}{l}\text { Gujarat: Mehsana, Gandhinagar, Bhavnagar, } \\
\text { Ahmedabad } \\
\text { Madhya Pradesh: Agar, Shajapur, Mandsaur, } \\
\text { Chindwara }\end{array}$ \\
\hline Aonla & Uttar Pradesh: Pratapgarh \\
\hline Mentha & Uttar Pradesh: Barabanki \\
\hline Guava & Uttar Pradesh: Kanpur \\
\hline \multirow{6}{*}{$\begin{array}{l}\text { All } \\
\text { horticulture } \\
\text { crop mapping }\end{array}$} & Maharashtra: Nashik \\
\hline & Himachal Pradesh: Kangra \\
\hline & Madhya Pradesh: Agar Shajapur \\
\hline & Mizorum: Serchhip \\
\hline & Karnataka: Tumkur \\
\hline & Punjab: Ludhiana \\
\hline
\end{tabular}

Table 1. Studies conducted for crop inventory and their study areas

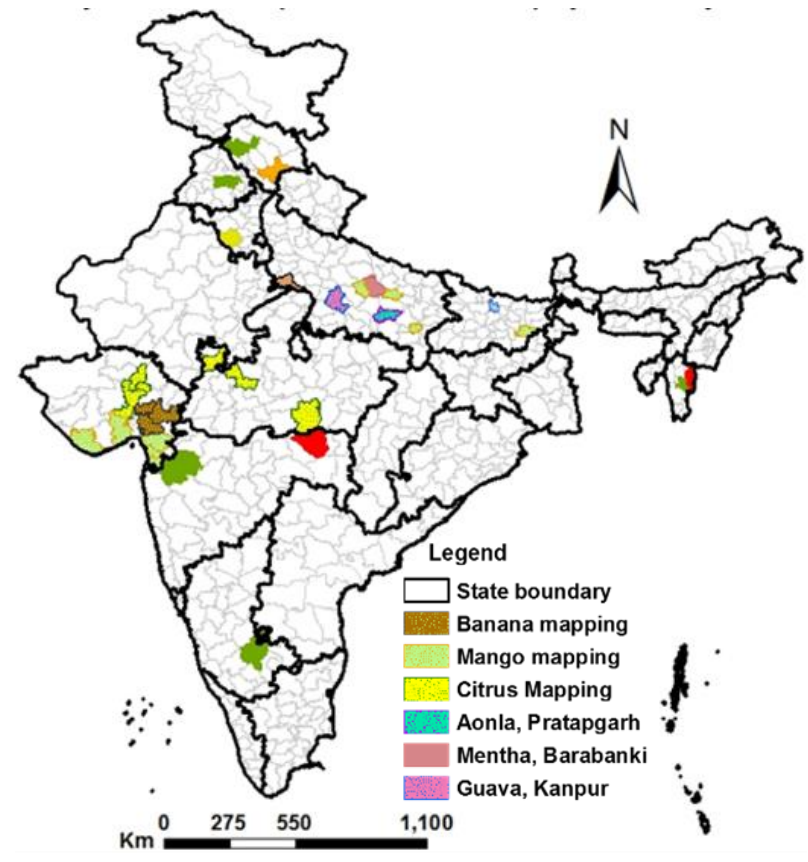

Figure 1: Distribution of study districts for different crops

The State Remote Sensing Applications Centres in collaboration with SAC have also made the complete horticulture crop mapping in different districts (states) Viz. Nashik (Maharashtra), Kangra (Himachal Pradesh), Agar \& Shajapur (MP), Serchip (Mizorum), Tumkur (Karnataka) and Ludhiyana (Punjab) in India (Table 1, Figure 1). Out of all these studies only one example is discussed here due to page limitation of the paper.

\section{METHODOLOGY}

\subsection{Pre-processing of satellite data}

The pre-processing steps consisted Geometric Correction followed by radiometric correction in order to minimize geometric and radiometric errors. Initially the digital numbers were converted to radiance as per equation (1) followed by conversion to Top of the Atmosphere (TOA) reflectance or apparent reflectance images using equation (2).

Radiance $\left(L_{\lambda}\right)=\frac{D N}{D N_{\max }}\left(L_{\max }-L_{\min }\right)+L_{\min }$

Where, $\quad L_{\min }=$ Minimum Radiance, $L$ max $=$ Saturation Radiance, $D N_{\max }=$ Radiometric Resolution

$$
\operatorname{TOA}\left(\rho_{\lambda}\right)=\frac{\pi \cdot L_{\lambda} \cdot d 2}{E_{0} \cdot \operatorname{Cos}(\theta)}
$$

Where,$\quad \mathrm{L} \lambda=$ Spectral Radiance $(\mathrm{mW}$ cm-2 ster- $1 \mu \mathrm{m}-1)$

$\mathrm{d} 2=$ Sun distance in astronomical unit (AU)

$\Theta=$ Sun zenith angle in radians.

$\mathrm{E}_{0}=$ Mean Solar Exoatmospheric irradiance $(\mathrm{mW}$ $\left.\mathrm{cm}^{-2} \mu \mathrm{m}^{-1}\right)$

\subsection{Ground truth (GT) planning and data collection}

Unsupervised output and Google earth is referred for preparing layout of maps from FCC in the scale of 1:15000 for GT target areas. Layout would include orchard region (congregate and mix as well), overlaid with route map and administrative (district/ taluk /village) boundaries.

a) Referring to layouts generated, GT data collection is carried out.

b) Details required in the ground data form are filled in Chaman App as well as in printed forms.

c) Selection of Area of Interests (AOI) using Ground Truth Points.: According to GT observations AOI are taken over image and signature from every class is marked to form a signature file.

\subsection{Classification and area estimation}

2.3.1 Pixel-Based-Unsupervised Classification: Stepwise orchard mapping using Remote Sensing and GIS was done as per the procedure narrated in flowchart (Figure 2). The preprocessing of the procured satellite data was performed (image to image geo-registration, convert radiance to TOA reflectance, convert DN to radiance, computation of the NDVI etc.). The first unsupervised classification was carried out separately over each LISS- 4 scene for 2 dates using ISODATA algorithm for identifying non-agriculture classes like forest, water or built up which were masked out to obtain the agricultural area. The classified output was clubbed together in 5 major classes viz. Orchard, Fields, Fallow Water, Urban based on spectral values and visual tone and texture detection. Based on the output, nearly 20 points for confusion classes and orchard classes located and planned to be verified by taking a ground truth of the region.

Supervised Classification: Post ground truth collection, the class signatures were collected by overlaying the collected GT points over the image and the second unsupervised classification was performed using Maximum Likelihoods Classifier (MXL) to classify the orchards. Post classification 
process like re-coding and scene mosaic and elimination of mixed pixel clusters were performed on the study region. It was followed by performing the logical modelling from the two date scene mosaic. For better classification, in general, the RS data of two dates were used with a caution that at least one from summer season when other field crops have least population. For citrus (Singh et al., 2016), used LISS-III and LISS-IV data of two dates in order to identify the orchard area and also found better accuracy with LISS -IV data. For banana, the union of classified data of two dates were used to estimate the gross banana acreage (Nishant et al. 2016).

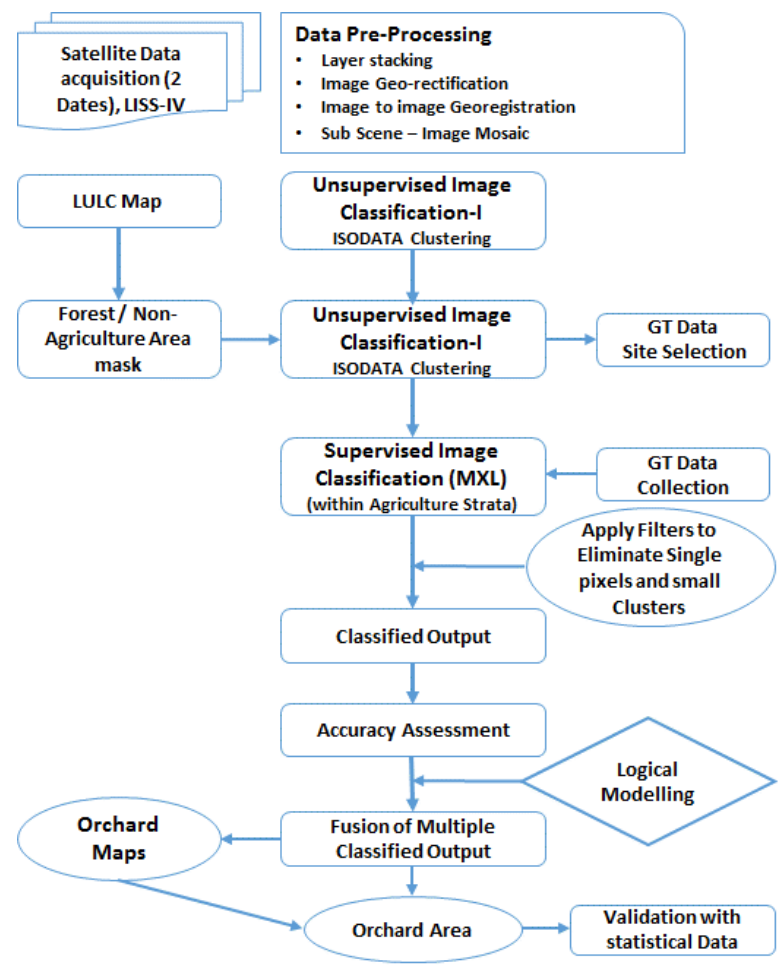

Figure 2. Step-wise algorithm for orchard mapping

2.3.2 Object-based Classification: Object based classification has an advantage that treat whole orchard field as a single segment that overcome the limitation of the pixel based classification that treats soil exposed in space between to two plant canopies as separate class (Hebbar et al. 2014, Roy et al. 2018). The methodology framework and step-wise flowchart for object based classification is as shown in Figure 3.

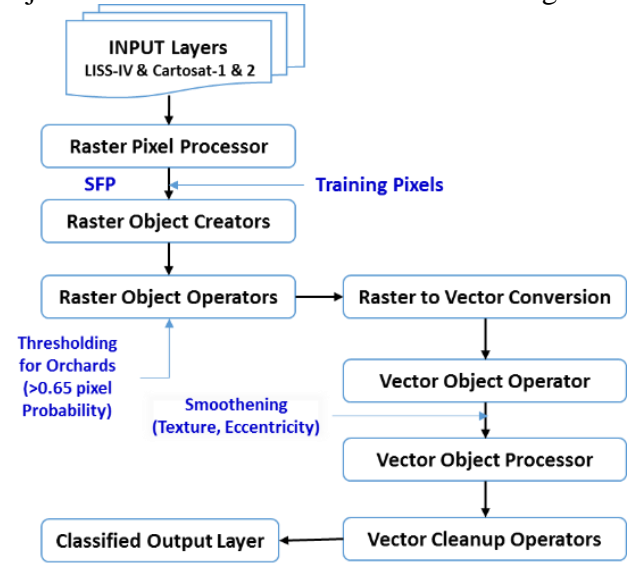

Figure 3. Methodology for Object-based classification and acreage estimation
Semi-automatic feature extraction model was used for delineation of plantation crops of the study area. Object oriented classification was done using high-resolution data. RESOURCESAT LISS-IV and Cartosat-1 PAN data along with the merged data was used as source data for the feature extraction model. LISS IV and merged LISS-IV and CARTOSAT was used as input for generation of Spectral feature probability (SFP). The definition of training areas for plantations as well as for background pixels is of central importance in the classification process. The SFP layer was converted into raster objects using threshold and clump function resulting in pixel probability layer. A set of raster and vector operators such as probability filter, eliminate and size filter was employed in the subsequent steps for generating the thematic map in vector format.

The object based classification considers the additional parameters like size, shape, colour, texture to assign the pixels in a particular class. The raster segments are first created and then converted to the vectors. The post classification smoothing was performed to remove the redundant classes and final classification output was generated

\subsubsection{Using very high resolution data and Google Earth interface (used for citrus in Maharashtra):}

Fruit crop inventory was carried out tehsil wise using high resolution data available on the Google Earth interface. Tehsil wise area of interest (AOI) in $\mathrm{kml}$ format was generated and overlaid on the high resolution images (fig 4). Data acquisition date in the form of grids were marked on the satellite data. These dates help us to understand the base line years of mapping activities. Cadastral boundaries were overlaid on the satellite data to mark the orientation of orchards and its exact alignment with the parcel boundaries. Individual orchards were marked, instead of cluster though lying adjacently planted. This would help us in future to attach the individual ownership to orchards, based on cadastral details. On the basis of visual appearance, texture and vigour coupled with ground truth information, orchards were grouped into categorise viz., age $(<5$ yrs., 5-10 yrs. \&>10 yrs.), health (poor, moderate \& good) and uniformity (non-uniform, moderately uniform \& uniform plant stand). This interpreted $\mathrm{kml}$ file was then converted to GIS compatible .shp file and overlaid on available LISS-IV satellite data and again corrected spatially to achieve positional accuracy. The orchards other than citrus were attributed as 'Other orchards'. Individual orchard counts in a particular village, their acreage and status (age, health \& plant stand) were analysed using above approach for selected villages.

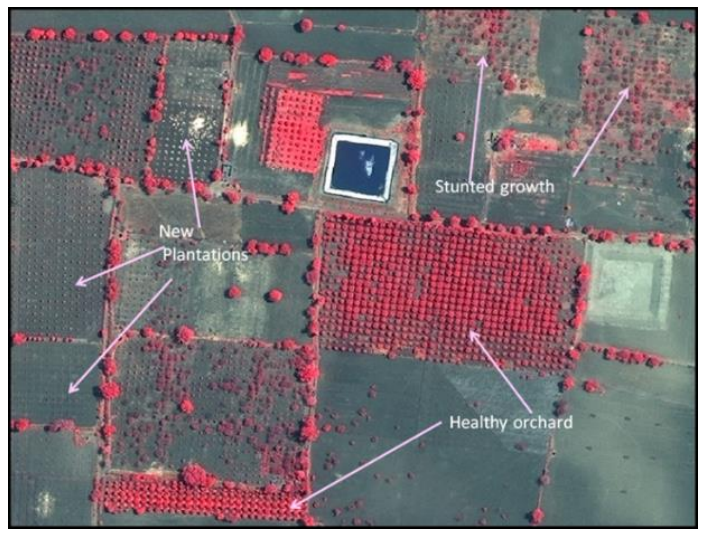

Figure 4. Different aged orchards on satellite image (Google Earth interface) 


\subsection{Complete Horticulture Inventory}

An attempt has been done to estimate and map the all possible horticulture crops in the selected districts viz. Nashik (Maharashtra), Kangra (Himachal Pradesh), Agar \& Shajapur (MP), Serchip (Mizorum), Tumkur (Karnataka) and Ludhiyana (Punjab) in India (Table 1, Figure 1). The method remains the same as it is for individual crops, the only difference that multiple crops were classified based on best suitable model. When both vegetables and orchards were classified, the pixel based supervised classification was better for vegetable crop (e.g. Onion crop in Nashik) classification while object based classification was better for orchard crops (e.g. pomegranate, grapes, citrus in Nashik district, Maharashtra state).

\subsection{Accuracy Assessment}

Field verification for classified data was carried out for post classification accuracy. Confusion matrix was generated between classes of citrus/mango orchards, other land use classes. Accuracy of different dates was assessed. The quality evaluation of the project outputs was made by independent team comprised with the members from MNCFC, NRSC, State Remote Sensing Centres and State Horticulture Departments and SAC (Table 2).

\section{RESULTS AND DISCUSSION}

\subsection{Mango}

Mango orchards in selected districts viz. Bhavnagar, Junagarh, Navsari, Surat and Valsad in Gujarat; Faizabad, Lucknow and Varanasi in Uttar Pradesh and Bhagalpur in Bihar were classified using both the methods i.e. Pixel based (hybrid of unsupervised and supervised) and object based classifiers explained in section 2.3.1 and 2.3.2. Mango orchard area was estimated and the derived area was compared with the statistical area of the region or district reported earlier from available sources (Table 2). Overall, classification accuracy was 80 to $90 \%$. The relative deviation of the RS estimated mango area compared the area reported by the state Department of Horticulture were upto $37 \%$ as shown in Table 2. The higher deviations also suggest the over or under reported area by the Department. The area distribution of mango in the districts of Gujarat and Uttar Pradesh is shown in figure 5. In pixel-based approach, April and May month satellite images had better accuracy because most of the field crops are harvested and spectral mixing is comparatively less as compared to other seasons. Also, images are mostly cloud free. In comparison to pixel based classification, object based classification is closer to reported statistics of state horticulture department (Table 2).
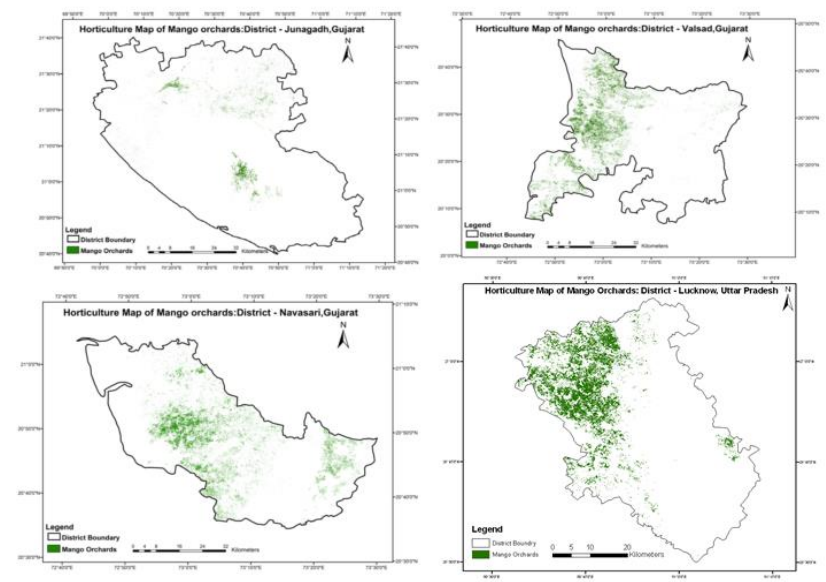

Figure 5. Classified Mango orchards for districts of Gujarat and Uttar Pradesh

\subsection{Banana}

Out of the three districts chosen for banana, Anand consists of largest contiguous patches followed by Bharuch and Vadodara (figure 6). In Anand the largest patches are present in Borsad taluka where as in Bharuch the contiguous patches can be seen in Jhagadia taluka. Analysis shows how the statistically available data and area estimated from remotely sensed data are almost equal with an accuracy ranging from $88 \%$ to $98 \%$. Deviation of the banana acreage from the statistical data of the same year was observed to range between 3 to $19 \%$. The main reasons for high deviations from statistical data and lower accuracy in Anand district can be attributed to the small plots and/or poor biomass could not be detected by the LISS-III sensor used. Object based area estimation of banana was done for Borsad taluka of Anand district only (Figure 7).

The accuracies and area estimates achieved with pixel based classifications of LISSS-III and LISS-IV data were comparable due to presence of large patches of banana in Borsad, with the effect that there were lesser incidences of pixel mixing for that area. Whereas object oriented Classification estimates, lesser area compared to maximum likelihood classification (Figure 7), which may be attributed to high intrinsic heterogeneity that results in its better classification.

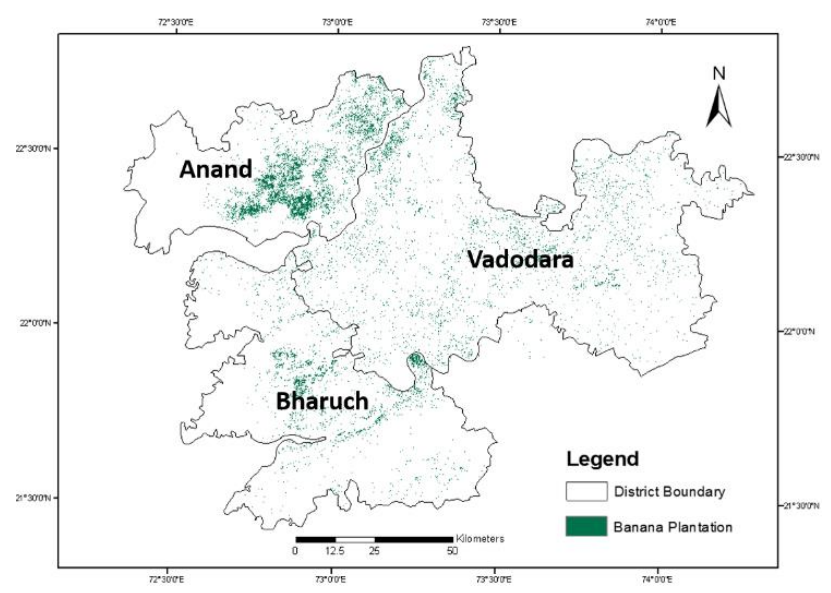

Figure 6. Spatial distribution of banana in Anand, Bharuch and Vadodara districts of Gujarat 


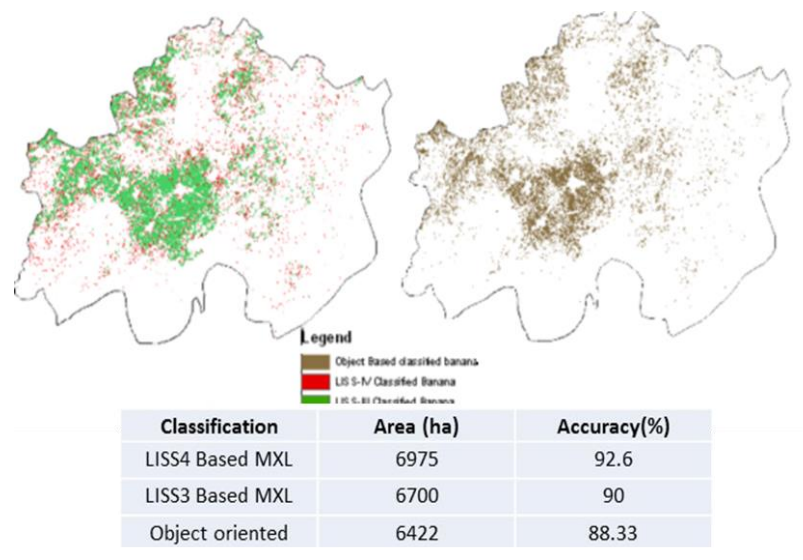

Figure 7. Pixel and object-based classification for banana in Borsad Taluka of Anand district

An attempt has also been made to classify the banana crop using microwave SAR data of RISAT -1 FRS data of the date October 5, 2015. It was compared with the classified banana crop using the optical sensors LISS IV data of two dates November 6 and December 24, 2015 (Figure 8). It was found that the classified banana crop was more in December month as compared to November because of incremental sowing in each month. The area classified with RISAT data was in close agreement to the banana area classified with optical LISS IV sensor of the nearest available date of November month (Figure 8), that shows the ability of microwave data to detect banana plantation at early stage and under cloudy sky conditions.

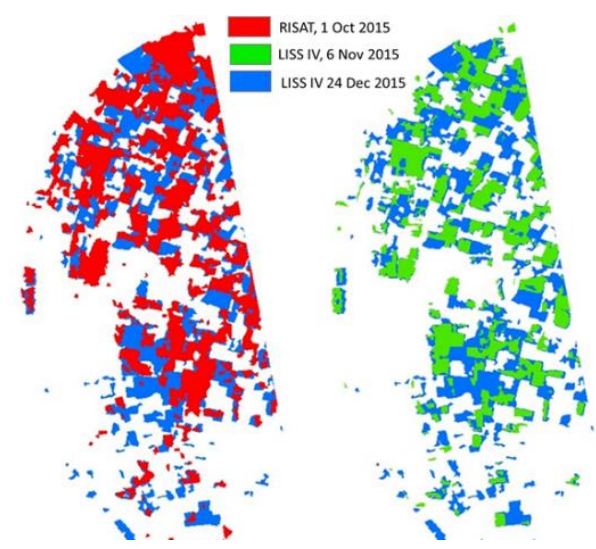

Figure 8. Comparison of banana classified using RISAT and LISS IV data

\subsection{Citrus}

For the citrus crop inventory, eight districts were selected i.e. four each in Gujarat and Madhya Pradesh state (Table 1). There many hybrids of citrus are grown in India among which citrus grown in Gujarat state are generally lime (Citrus aurantiifolia L.) and lemon (Citrus limon) while in Madhya Pradesh it is sweet orange (Citrus sinensis) in majority. As per the earlier study (Sigh et al. 2016) made in Mehsana district of Gujarat State, it was found that orchard area classified with MXL classification showed overall accuracy of $68.25 \%$ while objectbased classification method had accuracy of $76.47 \%$. With merged product of LISS IV and CARTOSAT, the accuracy obtained for citrus was $79.95 \%$. The area distribution of the citrus orchard by MXL, object based and merged product of LISS IV and CARTOSAT is shown in figure 9 and 10 respectively. Based on the conclusion, here, the hybrid method i.e. merged product of LISS IV and CARTOSAT was used to estimate the area under citrus crop for all the study districts.

The final citrus crop area estimated in eight study districts was given in Table 2. The highest citrus area was observed in Mehsana district in Gujarat and Agar district in Madhya Pradesh. The classification accuracy was ranged from $82 \%$ in Ahmedabad district to $88 \%$ in Gandhinagar district.
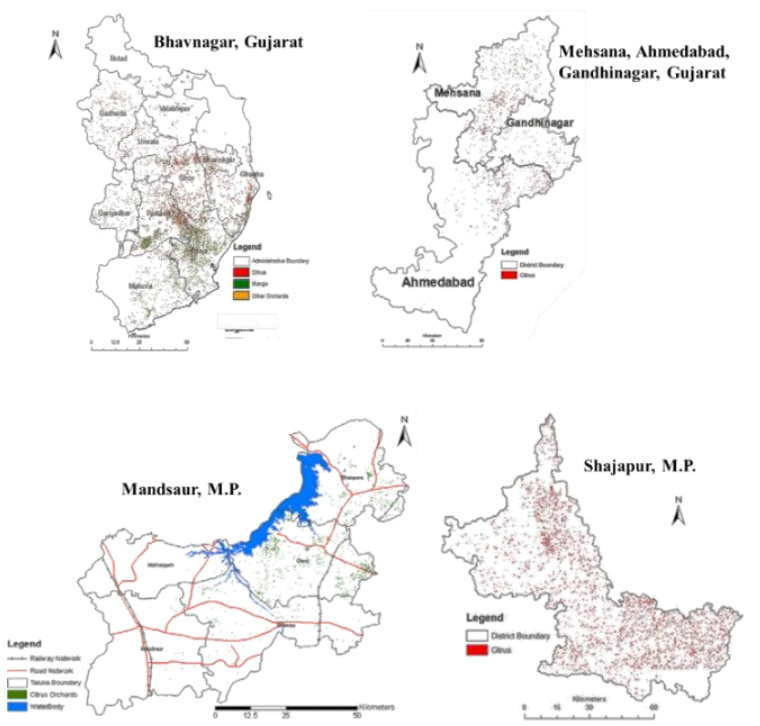

Figure 9. Classified Citrus orchards for districts of Gujarat and Madhya Pradesh using object based classification

\subsection{District level complete horticultural crops inventory - Case studies}

Few case studies were carried out for the complete horticultural mapping that include the all orchard crops grown in a district viz. Nashik (Maharashtra), Kangra (Himachal Pradesh), Agar \& Shajapur (MP), Serchip (Mizorum), Tumkur (Karnataka) and Ludhiyana (Punjab) in India (Table 1, Figure 1). Here the example of Nashik district in Maharashtra was shown in Figure 11 for classified orchards of Pomegranate, Grapes, Citrus etc. along with the land use map. The multi-date Resourcesat -2 LISS IV data merged with Cartosat -2 PAN data were used to discriminate all three orchards from other agricultural field crops.

In Nashik district, pomegranate orchards occupied the highest area of 25088.72 ha followed by grapes 13532.63 ha. Though the Nashik city is famous for orange (Citrus sinensis) market, the area under citrus crop was very less only 15.55 ha.

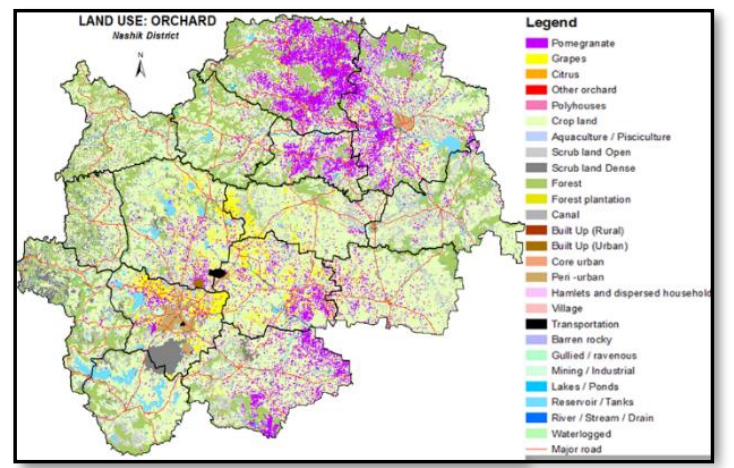

Figure 11. Mapping of Pomegranate, Grapes, Citrus on Land use map in Nashik, Maharashtra 


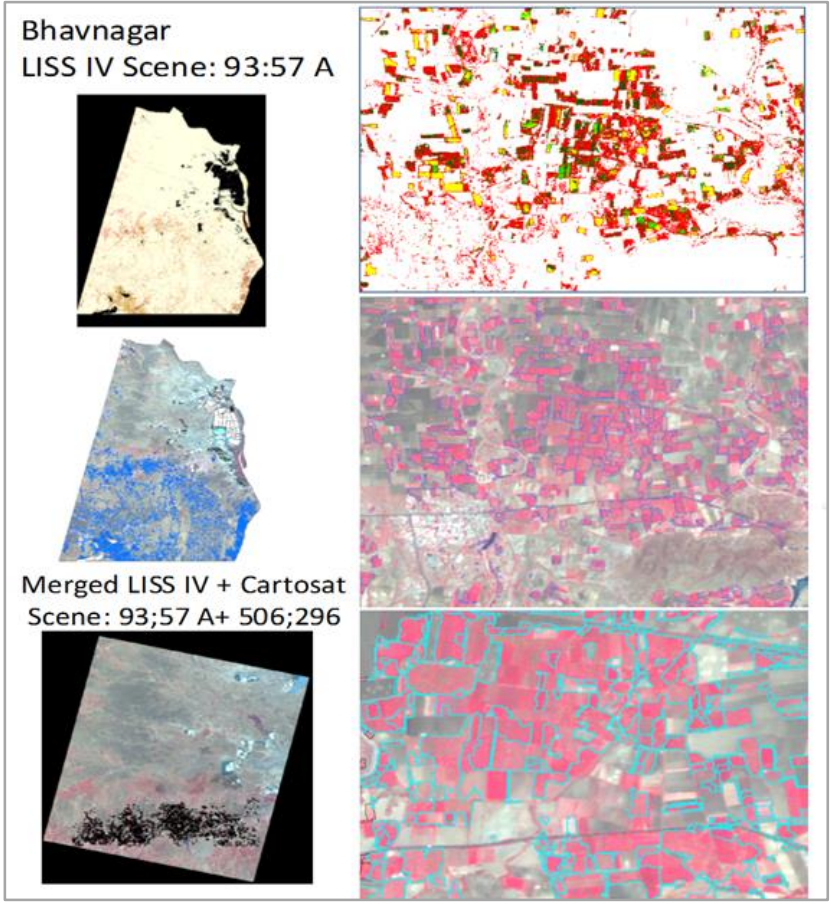

Figure 10. Orchard classification using merged product of LISS - IV and CARTOSAT-2

\subsection{Accuracy Assessment}

Field verification for classified data was carried out for post classification accuracy. Confusion matrix was generated between classes of citrus/mango orchards, other land use classes. Accuracy of different dates was assessed (Table 2).

\begin{tabular}{|c|c|c|c|c|c|}
\hline \multirow[b]{2}{*}{ Crop } & \multirow[b]{2}{*}{ District } & \multirow{2}{*}{$\begin{array}{c}\text { Classifica } \\
\text { tion } \\
\text { Accuracy } \\
(\%) \\
\end{array}$} & \multicolumn{2}{|c|}{ Area (ha) } & \multirow[b]{2}{*}{$\begin{array}{l}\text { RD } \\
(\%)\end{array}$} \\
\hline & & & $\begin{array}{c}\text { RS } \\
\text { Estimate }\end{array}$ & $\begin{array}{c}\text { State } \\
\text { statistics }\end{array}$ & \\
\hline \multirow{3}{*}{ Banana } & Anand & 90.03 & 19239 & 12558 & 19.00 \\
\hline & Bharuch & 98.53 & 15893 & 15420 & 3.06 \\
\hline & Vadodara & 88.37 & 5698 & 10401 & 5.28 \\
\hline \multirow{9}{*}{ Mango } & Navasari & 85.00 & 24251 & 26525 & -8.57 \\
\hline & Valsad & 80.00 & 28510 & 30107 & -5.30 \\
\hline & Junagadh & $>85.00$ & 23481 & 21557 & 8.92 \\
\hline & \begin{tabular}{|l} 
Surat \\
\end{tabular} & $>83.00$ & 8972 & 9267 & -3.18 \\
\hline & Bhavnagar & 85.66 & 3987 & 6401 & -37.71 \\
\hline & \begin{tabular}{|l} 
Lucknow \\
\end{tabular} & 90.91 & 29886 & 27806 & 7.48 \\
\hline & Faizabad & 90.00 & 7126 & 7224 & -1.36 \\
\hline & Varanasi & $>85.00$ & 1162 & 998 & 16.43 \\
\hline & Bhagalpur & & 6012 & & \\
\hline \multirow{7}{*}{ Citrus } & Mehsana & 86.00 & 9789 & 10760 & -9.02 \\
\hline & Gandhinagar & 88.00 & 1866 & 2063 & -9.55 \\
\hline & Bhavnagar & 87.26 & 6142 & 6955 & -11.69 \\
\hline & Ahmedabad & 82.29 & 1198 & 1331 & -9.99 \\
\hline & \begin{tabular}{|l|} 
Agar \\
+Shajapur
\end{tabular} & $>85.00$ & 25991 & 38040 & -31.67 \\
\hline & Mandsaur & $>85.00$ & 10828 & 9600 & 12.79 \\
\hline & Chindwara & $>85.00$ & 6596 & $\begin{array}{r}\text { Not } \\
\text { available }\end{array}$ & \\
\hline
\end{tabular}

Table 2. Crop area of banana, mango and citrus in their major growing districts, classification accuracy and relative deviations compared to reported area
The quality evaluation of the project outputs was made by independent team comprised with the members from MNCFC, NRSC, State Remote Sensing Centres and State Horticulture Departments and SAC Overall, the classification accuracy was more than $80 \%$ for all the crops. Deviation from statistics were in the range of 3 to $38 \%$. Higher deviations from statistics were mostly due to use of lower resolution satellite data or mixing of crops having similar spectral signatures e.g. mango and sapota in Navsari and Valsad districts of Gujarat. It was very difficult to discriminate the young orchards of 2-3 years from other field crops due to mixed / inter cropping practices.

\section{CONCLUSION AND FUTURE WORK}

The study presented in this paper, showed the usefulness of satellite remote sensing data for crop area estimation of major horticultural crops. The study also brought out issues like low accuracy for some young horticultural crops due to mixed or inter-cropping with other field crops. The mixing of sapota crop with mango was observed in Navsari and Valsad districts of Gujarat. The maps were checked and certified by respective State Horticulture Departments and were archived in VEADS, SAC (https://vedas.sac.gov.in) and BHUVAN, NRSC (https://bhuvan.nrsc.gov.in) geoportals of ISRO. RISAT - 1 (microwave) data were explored for the estimation of banana orchards in order to detect banana plantation at early stage and under cloudy sky conditions. There is huge potential of application in this sector using advanced observations from hyperspectral, thermal infrared sensors and advanced radars or LIDAR's on-board upcoming satellites. The yield estimation, especially for orchard crops posed a challenge. However, this was for the first time in the country, where such coordinated work for horticulture inventory was carried out using satellite data. This project also resulted in capacity building of large number of state horticulture department officials, who strongly contributed to the work. Based on the success of this project, the Ministry of Agriculture has launched the Phase II of the CHAMAN project, whose main purpose is to operationalise the technologies developed in CHAMAN Phase I.

\section{ACKNOWLEDGEMENT}

The authors are thankful to Director, Space Applications Centre and Deputy Director, Earth, ocean, atmosphere and Planetary Sciences \& applications Area, SAC for their support and encouragement. The work presented in this paper was carried out under the CHAMAN project funded through the Mission for Integrated Development of Horticulture of the Department of Agriculture, Cooperation and Farmers' Welfare (DAC\&FW). Authors thankfully acknowledge the Secretary, DAC\&W for funding the project and Advisor (Horticulture) and Director, MNCFC of DAC\&FW, for time to time critical review of the project and for their valuable suggestions. Thanks are also due to the State Horticulture Departments and State Remote Sensing Centres for their support in field data collection and image analysis.

\section{REFERENCES}

Anonymous. 2017. Horticultural Statistics at a Glance 2017, Horticulture Statistics Division, Department of Agriculture, Cooperation \& Farmers Welfare, Ministry of Agriculture \& Farmers Welfare, Government of India, pp. 481. 
Hebbar, R., Ravishankar, H. M., Trivedi, S., Subramanian, S.R., Uday Raj and Dadhwal, V.K. 2014. Object oriented classification of high resolution data for inventory of horticultural crops. The International Archives of the Photogrammetry, Remote Sensing and Spatial Information Sciences, Volume XL-8, 2014, ISPRS Technical Commission VIII Symposium, 09 - 12 December 2014, Hyderabad, India, pp. 745-749.

Kimothi, M.M., Kalubarme, M.H., Dutta, S., Thapa, R. and Sood, R.K. 1997. Remote sensing of horticultural plantations in Kumarsain tehsil in Shimla district, Himachal Pradesh: $J$. Indian Soc. Remote Sens. 25, pp. 19-26.

Nishant, Nilay, Upadhayay, Gargi, Vyas, S. P. and Manjunath, K. R. 2016. Banana orchard inventory using IRS LISS sensors. Proc. SPIE 9880. SPIE APRS, 2016, 4-7 April 2016, New Delhi.

Panigrahy, S. and Manjunath, K. R. 2009. Horticulture Studies (2000-2008): Highlights of the results and achievements of the project. Project Report. EOAM/SAC/AMD/HORT/PR/01/2009. Space Applications Centre, Ahmedabad.

Parihar, J. S. and Oza, S. R. 2006. FASAL: An integrated approach for crop assessment and production forecasting. Proceedings of SPIE - The International Society for Optical Engineering 6411.
Ray, S. S., Mamatha, S., Manjunath, K. R., Uday Raj, Seshasai MVR, Singh, K. K., Kimothi, M. M., Parihar, J.S. and Saxena, Mamta. 2016. CHAMAN: A National Level Programme for Horticultural Assessment \& Development. NNRMS Bulletin. 40: pp. 1-6.

Ray, S. S. and Neetu. 2017. Crop area estimation with Remote Sensing. In: J. Delincé (ed.), Handbook on Remote Sensing for Agricultural Statistics (Chapter 5). Handbook of the Global Strategy to improve Agricultural and Rural Statistics (GSARS): Rome. pp. 131-183.

Roy, Shreya, More, Revati, Kimothi, M.M., Mamatha, S., Vyas, S.P. and Ray, S.S. 2018. Comparative analysis of object based and pixel based classification for mapping of mango orchards in Sitapur district of Uttar Pradesh. Journal of Geomatics, 12(1): pp. 69-76.

Singh, N., Chaudhari, K.N., Manjunath, K. R., 2016. Comparison of Citrus Orchard Inventory using LISSIII \& LISSIV data. Proc. SPIE 9880, SPIE APRS, 2016, 4-7 April 2016, New Delhi.

Usha, K. and Singh, B. 2013. Potential applications of remote sensing in horticulture-A review. Scientia Hort. 153: pp. 7183 